\title{
Influence of Floating Monitoring Platform Structure on the Hydrostatic Characteristics
}

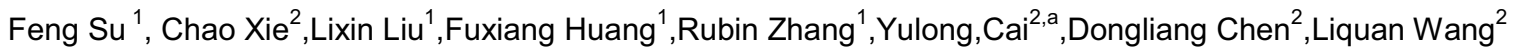 \\ ${ }^{1}$ Offshore Oil Engineering CO.LTD \\ ${ }^{2}$ Harbin Engineering University, PRC
}

\begin{abstract}
According to the environment and work styles, the underwater monitoring devices can be divided into three type, fixed monitoring device, the floating monitoring device and mobile monitoring device. Floating monitoring platform is a new type of monitoring device of the floating monitoring device, which is mainly used for underwater video monitoring of pool. as the floating platform monitoring in water motion and hydrostatic characteristics are closely related, the influent of counterweight, weight distance and floating body diameter of the structure parameters on its hydrostatic characteristics and the natural periods for roll, pitch and heave should be considered, In this work, the floating body diameter influent most, the counterweight followed, and the structure parameters have different influence on the natural periods for roll, pitch and heave, it need to be analyzed according to the concrete structure parameters.
\end{abstract}

\section{Introduction}

The underwater monitoring device has become variety which was utilized for Underwater observation such as marine archaeology, search, underwater construction, according to the working mode, it can be divided into three types, fixed monitoring device, floating monitoring device and mobile monitoring device, the floating monitoring device has the advantage of low cost, simple operation, monitoring variable area etc, when compared to other type. So it has been used in this work.

The floating monitoring platform was designed according to the principle of buoy and used gravity platform structure which could reduce the gravity centre according to the typical structure of offshore Spar platform due to insure the stability ${ }^{[1][2]}$.

Floating monitoring platform was refer to the principle of ship statics in the design process, and calculating the hydrostatic force characteristics by establishing the mathematical, which mainly include the calculation of buoyancy and stability.

\section{The principle of floating monitoring platform structure}

Floating monitoring platform is used for underwater video monitoring of pool, the working principle is shown in Figure.1.

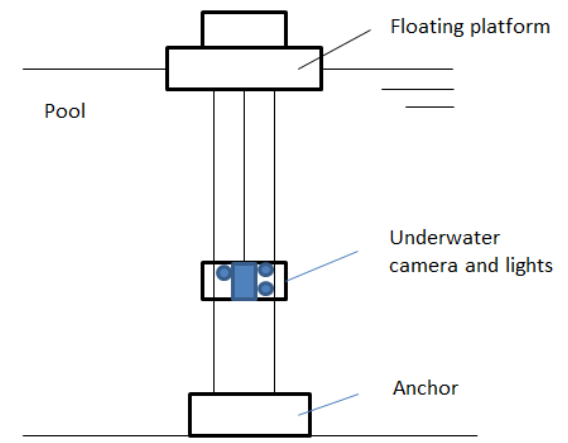

Figure.1 The working principle of floating monitoring platform

Practical work process: First, according to the actual monitoring requirements of the region, move it to the required monitoring area though the crane, Then, put down the anchor on the bottom of the pool by controlling the motor of platform. Next, put down the underwater lights and camera by using two cables as a track. Last, Multi-angle and multi-regional monitoring is realized by controlling the depth and the angle of the camera.

\footnotetext{
a Corresponding author:798455767@qq.com
} 


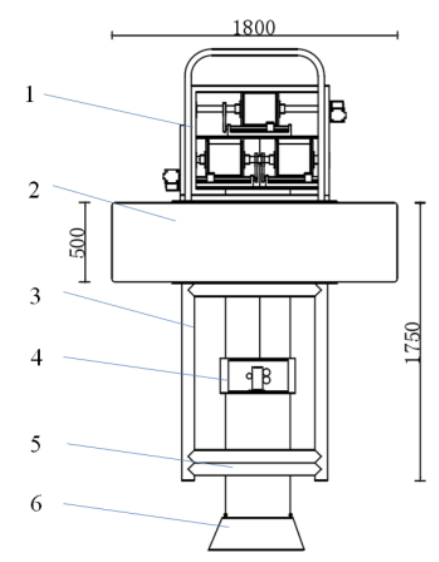

1-Windlass system 2-Floating body 3-Frame of floating monitoring platform 4-Underwater camera and lights 5 -Counterweight 6 -anchor

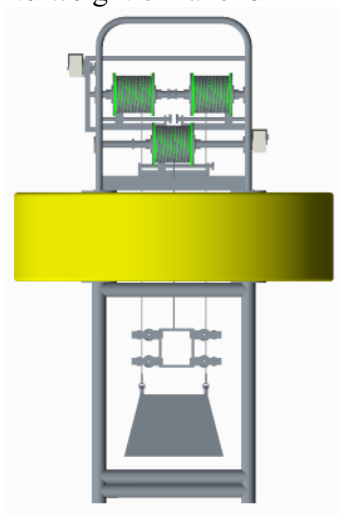

Figure.2 Floating monitoring platform structure and 3D assembly drawing

The frame of the floating platform is shown in Figure.2; Windlass system is used to control the lifting of the anchor and the camera. The Floating body is provided buoyancy for the floating platform, Counterweight is used to reduce the centre of gravity which could improve the anti-overturn capacity, and anchor is used to keep the position of the entire device.

The structure parameters can affect the movement characteristic in the pool through the analysis of the working process of the floating monitoring platform, in this work, the influence of the structure parameters of the counterweigh of distance(L), counterweight(M) and the floating body diameter(D) on its hydrostatic characteristics and natural periods of roll are considered.

\section{Parameters calculation}

\subsection{Small angle movement}

The floating monitoring platform make small angle movement in the pool is shown in Fig.3, the WL is waterline for balance, and the $W_{l} L_{1}$ is waterline for small angle of inclination, the and represent the change in volume of the wedge, the , is Centroid of volume of the wedge(equation 1$)^{[3]}$ :

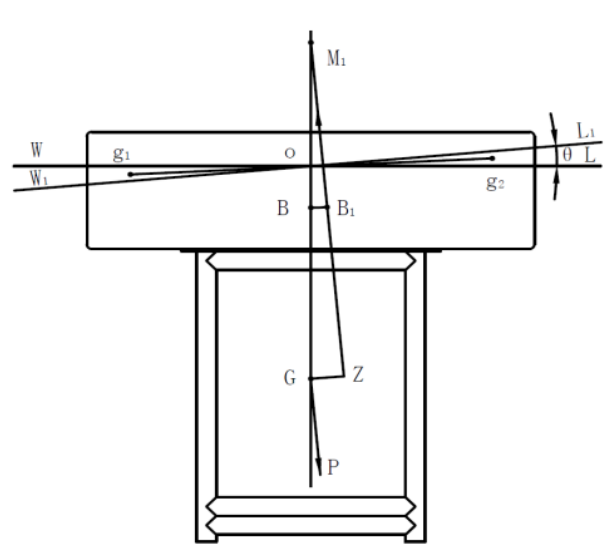

Figure.3 Small angle movement

$$
\overline{B B_{1}}=\frac{I_{x}}{\bar{V}} \cdot \theta
$$

Where:

$\overline{B B_{1}}$ is the distance of the centre of buoyancy move;

$I_{x}$ is the area moment of inertia;

$\theta$ is the angle of inclination;

$\mathrm{V}$ is the Drainage volume;

The distance $\left(\overline{B B_{1}}\right)$ is proportionate to the area moment of inertia $\left(I_{x}\right)$ and the angle of inclination $(\theta)$, and inversely proportional to the Drainage volume $(\mathrm{V})$ (equation 1). When the angle of inclination is small, $\overline{B B_{1}} \approx \overline{B B_{1}}=\overline{M B} \cdot \theta$, the Radius of stability is show blow $^{[3]}$ (equation 2 ).

$$
r=\frac{I_{x}}{V}
$$

\subsection{Calculation of floating and gravity center}

The total weight of the floating monitoring platform ${ }^{[4-6]}$ is calculated by equation 3 as fallow:

$$
P=p_{1}+p_{2}+p_{3}+\ldots+p_{n}=\sum_{i=1}^{\mathrm{n}} p_{i}
$$

Where:

$P \quad$ is the total weight of the floating monitoring platform; $p_{i} \quad$ is the parts of the floating monitoring platform, $\boldsymbol{i}=\boldsymbol{n}$;

The center of gravity of the floating monitoring platform $\mathrm{G}\left(\mathrm{x}_{\mathrm{i}}, \mathrm{y}_{\mathrm{i}}, \mathrm{z}_{\mathrm{i}}\right)^{[4-6]}$ is calculated by equation 4 as fallow:

$$
x_{g}=\frac{\sum_{i=1}^{n} p_{i} x_{i}}{\sum_{i=1}^{n} p_{i}}, y_{g}=\frac{\sum_{i=1}^{n} p_{i} y_{i}}{\sum_{i=1}^{n} p_{i}}, z_{g}=\frac{\sum_{i=1}^{n} p_{i} z_{i}}{\sum_{i=1}^{n} p_{i}}
$$

Where:

$\mathrm{x}_{\mathrm{g}}, \mathrm{y}_{\mathrm{g}}, \mathrm{Z}_{\mathrm{g}}$ is the centre of gravity of the floating monitoring platform, $\mathrm{mm}$.

$\mathrm{x}_{\mathrm{i}}, \mathrm{y}_{\mathrm{i}}, \mathrm{z}_{\mathrm{i}}$ is the centre of gravity of the part of the floating monitoring platform, $\mathrm{mm}$. 


\subsection{Colour illustrations Moment of section of the floating body}

The Moment of section of the floating body must been calculated before the radius of stability. The section of the floating body is shown in Figure. 4. The equation of the section of floating body is blow.

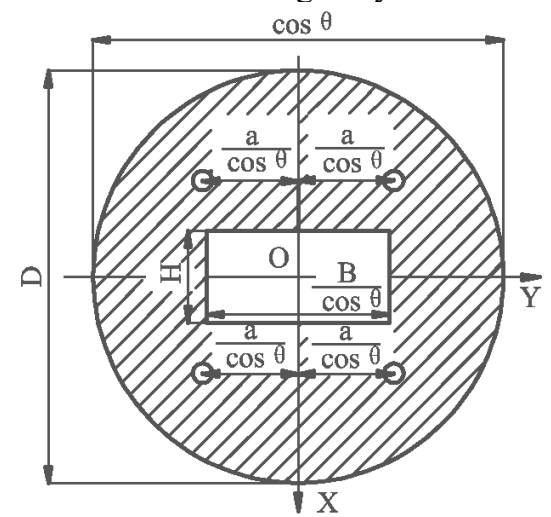

Figure.4 Section of the floating body

$$
I_{x}=\iint_{A} y^{2} d_{A}=\iint_{A 1} y^{2} d_{A 1}-\iint_{A 2} y^{2} d_{A 2}-4 \iint_{A 3} y^{2} d_{A 3}
$$

Where:

A1 is area of ellipse, $m^{2}$.

$A 2$ is area of rectangular,. $\mathrm{m}^{2}$

$A 3$ is area of four little rectangular $\mathrm{m}^{2}$,

$$
I_{x}=I_{x C}+a^{2} A
$$

Where:

$I_{x C}$ is the section of the floating body for axis of $x_{\mathrm{c}}$.

$a$ is the distance between centroid and axis $\mathrm{x} . \mathrm{m}$.

A is the section area, $\mathrm{m}^{2}$.

The equation is calculated by united equation 5 and equation 6 :

$$
I_{x}=\frac{\pi \mathrm{D}^{4}-\frac{16}{3} H B^{3}-4 \pi d^{4}-64 \pi d^{2} a^{2}}{64 \cos ^{3} \theta}
$$

Where:

$\mathrm{D}$ is outer circle diameter of the floating body, $\mathrm{m}$;

$H$ is height of the middle Rectangular, m;

$B$ is length of the middle Rectangular, $\mathrm{m}$;

$d$ is diameter of the four hole, $\mathrm{m}$;

$a$ is distance between the hole and axis $\mathrm{x}, \mathrm{m}$;

$\theta$ is tilt angle of the floating monitoring platform, ${ }^{\circ}$.

\subsection{Stability parameter calculation}

Floating monitoring platform in the calculation of hydrostatic properties including the water floating and stability calculation, the calculation of stability including small angle stability and stability at large angles of inclination, taking into account the floating monitoring platform used in the pool, it is the wind and wave is almost zero, so the main consideration in this the initial stability. According to ship statics theory ${ }^{[3]}$, ship initial stability can be expressed according to three kinds of forms: height of stability(h), restoring $\operatorname{moment}\left(M_{r}\right)$, coefficient of stability (k).

The positive and negative of height of the stability can determine the stability of the floating monitoring platform in equilibrium position, the floating monitoring platform is stable when the height of stability is positive, the floating monitoring platform is unstable when the high stability is negative:

$$
h=z_{b}+r-z_{g}
$$

Where:

$z_{b} \quad$ is coordinate of the axis $\mathrm{Z}$ of floating heart, $\mathrm{m}$;

$r$ is radius of the stability, $\mathrm{m}$;

$z_{g}$ is coordinate of the axis $\mathrm{Z}$ of the centre of gravity, $\mathrm{m}$;

The ability to get into balance is more easier or the floating monitoring platform is more stable when restoring moment $\left(M_{r}\right)$ is more bigger:

$$
M_{r}=P \cdot(r-a) \cdot \sin \theta
$$

Where:

$a \quad$ is distance between the center of gravity and floating heart, , $\mathrm{m}$;

$P$ is gravity of the floating monitoring platform, $\mathrm{N}$.

The coefficient of stability is product of the displacement and the height of stability, and it is used to determine the stability of the floating monitoring platform:

$$
k=P h
$$

The platform is stable when $k>0$, The platform is unstable when $k<0$.

\subsection{The natural period of roll and heave}

\subsubsection{The natural period of roll and pitch}

The natural period of roll and pitch are calculated respectively as the floating monitoring platform adopts the symmetrical structure design, the floating body shape in the horizontal and vertical are slightly different. According to the sea-keeping theory, the relationship is blow $^{[7][8]}$ :

$$
T_{\phi}=\frac{2 \pi}{n}=2 \pi \sqrt{\frac{J+\Delta J}{\Delta h}}
$$

Where:

$T_{\phi}$ is the natural period of roll, $\mathrm{s}$;

$n$ is the Frequency of roll, $\mathrm{rad} / \mathrm{s}$;

$J \quad$ is the Moment of inertia, $\mathrm{kg} \cdot \mathrm{m}^{2}$;

$\Delta J$ is the Additional inertia moment, $\mathrm{kg} \cdot \mathrm{m}^{2}$;

$\Delta$ is the displacement, $\mathrm{kg}$;

$\mathrm{H}$ is the height of stability, $\mathrm{m}$.

According to the experience of the buoy design, Moment of inertia have no effect on the natural period of 
roll, so using the Hoff Ade formula for approximate estimation(equation 12):

$$
J+\Delta J=\frac{D}{g} \rho^{2}
$$

Where:

$\mathrm{g}$ is Acceleration of gravity, $\mathrm{m} / \mathrm{s} 2$;

$\rho$ is radius of inertia, $\rho=c B, \mathrm{c}$ is empirical coefficient,

$\mathrm{B}$ is width of the floating body.

$D$ is diameter of the floating monitoring platform, $\mathrm{m}$.

A new equation is blow from equation 12 and equation 11:

$$
T_{\phi}=2 \pi \sqrt{\frac{D c^{2} B^{2}}{D h g}}=2.01 \frac{c B}{\sqrt{h}}
$$

Where :

$B$ is width of the floating body, m;

$c$ is empirical coefficient;

$h$ is height of the stability.

\subsubsection{The natural period of heave}

The equation of the natural period of heave is blow ${ }^{[7][8]}$ :

$$
T_{z}=\frac{2 \pi}{n_{z}}=2 \pi \sqrt{\frac{\frac{\Delta}{g}+\lambda}{\gamma S_{w}}}
$$

Where:

$T_{z}$ is natural period of heave, $\mathrm{s}$;

$n_{z}$ is the Frequency of heave, $\mathrm{rad} / \mathrm{s}$;

$\Delta \quad$ is displacement, $\mathrm{kg}$;

$g$ is acceleration of gravity, $\mathrm{m} / \mathrm{s} 2$;

$\lambda$ is the added-mass of heave, $\mathrm{kg}$;

$Y \quad Y=\rho g$

$S_{w}$ is area of the waterline, $S_{w}=4 C_{w} R^{2}, C_{w}$ is the coefficient of the waterline.

As the added-mass and the mass of the platform are in same level, take $\lambda \approx \Delta / g$, the displacement the floating monitoring platform is blow:

$$
\Delta=\omega \checkmark
$$

Where:

$\omega$ is the water density, $\mathrm{kg} / \mathrm{m}^{3}$;

$V$ is the displacement, $\mathrm{m}^{3}$;

The coefficient of area of waterline is blow:

$$
C_{w}=\frac{A_{w}}{(T \times B)}
$$

Where:

$C_{p}$ is prismatic coefficient of the floating body in vertical, $C_{p}=\frac{C_{B}}{C_{w}}$.
$C_{\mathrm{B}}$ is square coefficient, $C_{\mathrm{B}}=\frac{V}{L \times B \times T}$.

\section{Example}

In this work, the natural period of roll and heave is analyzed by change the distance of counterweight(L), counterweight(M) and the diameter of floating body(D),

\begin{tabular}{|c|c|c|c|c|c|}
\hline $\begin{array}{l}\text { Part } \\
\text { name }\end{array}$ & $\begin{array}{l}\text { Materi } \\
\text { al }\end{array}$ & $\begin{array}{l}\mathrm{Nu} \\
\mathrm{mbe} \\
\mathrm{r}\end{array}$ & $\begin{array}{l}\text { Wheth } \\
\text { er the } \\
\text { symm } \\
\text { etric } \\
\text { distrib } \\
\text { ution }\end{array}$ & $\begin{array}{c}\text { Weight } \\
\text { (water) } \\
(\mathrm{Kg})\end{array}$ & $\begin{array}{c}\text { Barycen } \\
\text { tric } \\
\text { coordin } \\
\text { ates }(\mathrm{x}, \\
\mathrm{y}, \mathrm{z}) \mathrm{mm}\end{array}$ \\
\hline Mount & $\begin{array}{l}\text { Alumi } \\
\text { nium } \\
\text { alloy }\end{array}$ & 1 & $\begin{array}{c}\text { Axis } \\
\mathrm{Y}\end{array}$ & 30 & $\begin{array}{c}(0,-110 \\
350)\end{array}$ \\
\hline Up-shelf & $235^{Q}$ & 1 & $\begin{array}{c}\text { Axis } \\
\mathrm{X} \text { and } \\
\mathrm{Y} \\
\end{array}$ & 28.5 & $\begin{array}{l}(0,0) \\
372)\end{array}$ \\
\hline $\begin{array}{c}\text { Down- } \\
\text { shelf }\end{array}$ & $235^{Q}$ & 1 & $\begin{array}{c}\text { Axis } \\
\mathrm{X} \text { and } \\
\mathrm{Y}\end{array}$ & $77(66)$ & $\begin{array}{c}(0,0,- \\
740)\end{array}$ \\
\hline $\begin{array}{l}\text { Counter } \\
\text { weight }\end{array}$ & $235^{Q}$ & 1 & $\begin{array}{c}\text { Axis } \\
\mathrm{X} \text { and } \\
\mathrm{Y}\end{array}$ & $\begin{array}{c}280(23 \\
7)\end{array}$ & $\begin{array}{c}(0,0,- \\
1600)\end{array}$ \\
\hline $\begin{array}{l}\text { Double } \\
\text { Windlas } \\
\text { S }\end{array}$ & $\begin{array}{l}45 \# \\
\text { and } \\
\text { Alumi } \\
\text { nium } \\
\text { alloy }\end{array}$ & 1 & $\begin{array}{c}\text { Axis } \\
\mathrm{Y}\end{array}$ & 13.3 & $\begin{array}{l}(0,0, \\
270)\end{array}$ \\
\hline $\begin{array}{c}\text { Single } \\
\text { Windlas } \\
\mathrm{s}\end{array}$ & $\begin{array}{l}45 \# \\
\text { and } \\
\text { Alumi } \\
\text { nium } \\
\text { alloy }\end{array}$ & 1 & $\begin{array}{c}\text { Axis } \\
\mathrm{X} \text { and } \\
\mathrm{Y}\end{array}$ & 10.1 & $\begin{array}{l}(0,0) \\
592)\end{array}$ \\
\hline $\begin{array}{l}\text { Linear } \\
\text { module }\end{array}$ & $\begin{array}{l}\text { Alumi } \\
\text { nium } \\
\text { alloy }\end{array}$ & 3 & $\begin{array}{c}\text { Axis } \\
Y\end{array}$ & 11.3 & $\begin{array}{l}(0,0) \\
100)\end{array}$ \\
\hline Motor & $\begin{array}{l}\text { Alumi } \\
\text { nium } \\
\text { alloy } \\
\text { and } \\
\text { Q235 }\end{array}$ & 2 & $\begin{array}{c}\text { Axis } \\
Y\end{array}$ & 14.6 & $\begin{array}{l}(0,0) \\
160)\end{array}$ \\
\hline Gear & Q235 & 1 & - & 7.6 & $\begin{array}{l}(0,- \\
459, \\
196)\end{array}$ \\
\hline $\begin{array}{c}\text { Floating } \\
\text { body }\end{array}$ & $\begin{array}{l}\text { Fiberg } \\
\text { lass } \\
\text { and } \\
\text { Foam } \\
9][10]\end{array}$ & & $\begin{array}{c}\text { Axis } \\
\mathrm{X} \text { and } \\
\mathrm{Y}\end{array}$ & 96 & $\begin{array}{c}(0,0,- \\
250)\end{array}$ \\
\hline $\begin{array}{c}\text { The } \\
\text { total } \\
\text { weight }\end{array}$ & & & & $\begin{array}{l}568.4( \\
514.4)\end{array}$ & \\
\hline
\end{tabular}
which is based on an existing floating monitoring platform. Specific data are shown in table 1 .

Table 1. Structure parameters of the floating monitoring platform. 


\section{Result}

In this work, the movement is affected by resistance of the water when the floating monitoring platform swing in the water, but now the motion of roll and heave was just been discussed in no damping.

\subsection{The influence of counterweight distance}

First, the center of gravity of the down-shelf is supposed to be no change for calculate conveniently, the change just happen in the center of gravity of the platform when the counterweight distance changes. The relationship between the height of $\operatorname{stability}(\mathrm{H})$,restoring moment(M) and coefficient of $\operatorname{stability}(\mathrm{K})$ with distance of counterweight $(\mathrm{L})$ in the change of the tilt $\operatorname{angle}(\theta)$ is below.

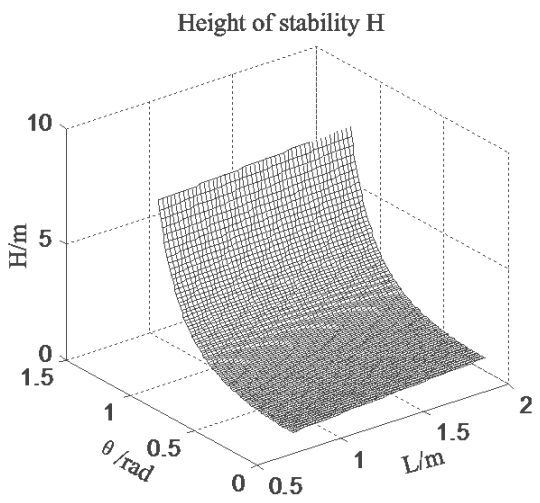

Figure.5 The height of stability

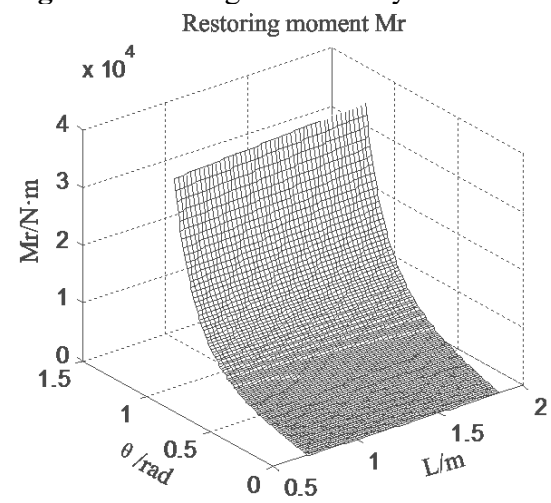

Figure.6 The restoring moment

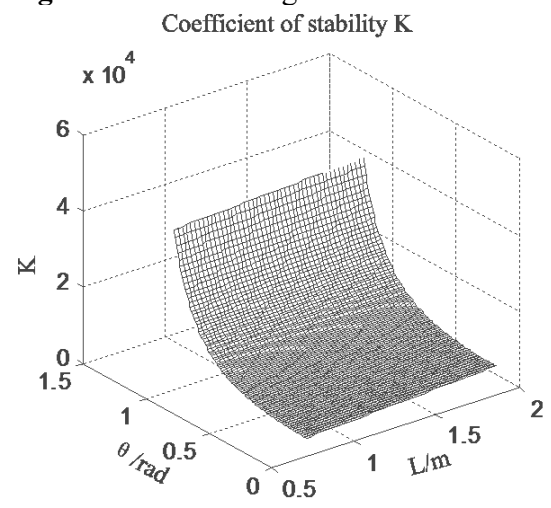

Figure. 7 The coefficient of stability

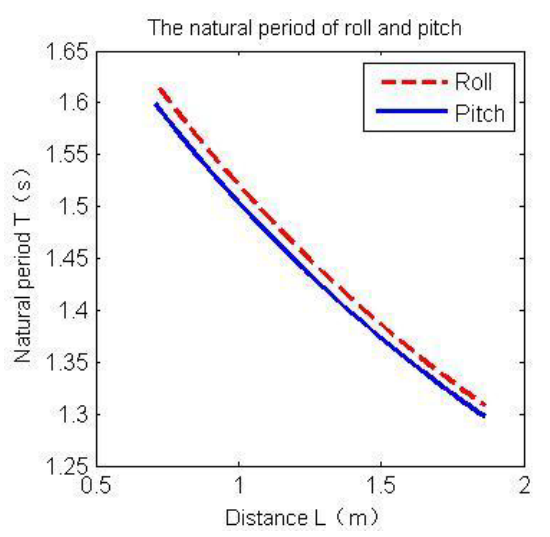

Figure.8 The natural period of roll and pitch

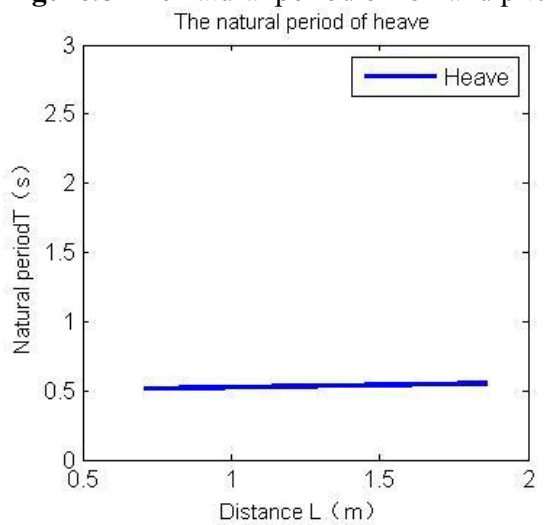

Figure.9 The natural period of heave

Figure.5 to Figure.7 show the stability is increased when the platform is in the same tilt angle while the counterweight distance become bigger, for example, in Figure 5, the height of stability is $0.9775 \mathrm{~m}$ while the counterweight distance is $0.735 \mathrm{~m}$ when the tilt angle is $0^{\circ}$, but the height of stability is $1.48 \mathrm{~m}$ when the counterweight distance is increase to $1.86 \mathrm{~m}$. So the counterweight distance could increase the stability of the platform. Figure. 8 show that the counterweight distance increase could reduce the natural period of roll and pitch. Figure.9 show the counterweight distance influent the natural period of heave slightly which could been ignored.

\subsection{The influence of counterweight}

First, making the counterweight( $\mathrm{M})$ change in the section of $[0,500 \mathrm{Kg}]$, and when $\mathrm{M}=0$, the down-shelf is exist and its length is $1.75 \mathrm{~m}$, when the $M$ increased, the section of the floating body won't change, and the area of the waterline won't change too for calculated conveniently. The relationship between the height of stability $(\mathrm{H})$,restoring $\operatorname{moment}(M)$ and coefficient of stability $(\mathrm{K})$ with counterweight $(\mathrm{m})$ in the change of the tilt angle $(\theta)$ is below: 


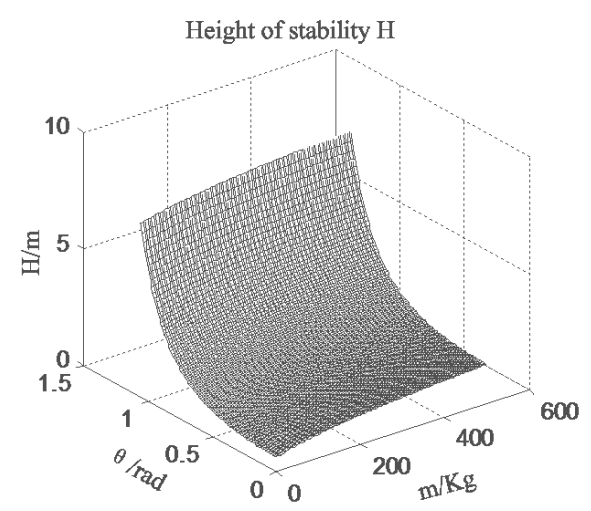

Figure.10 The height of stability

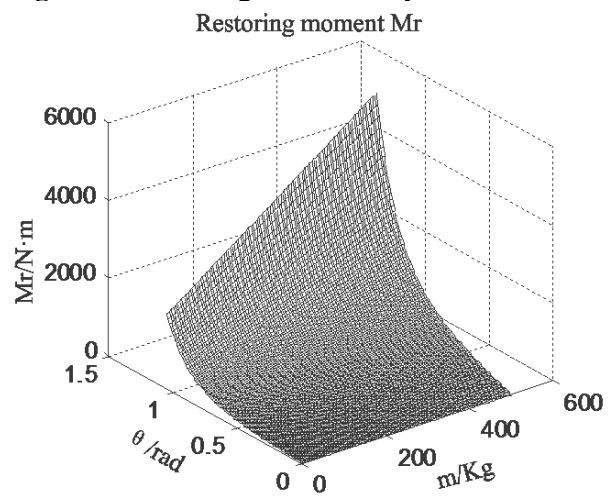

Figure.11 The restoring moment

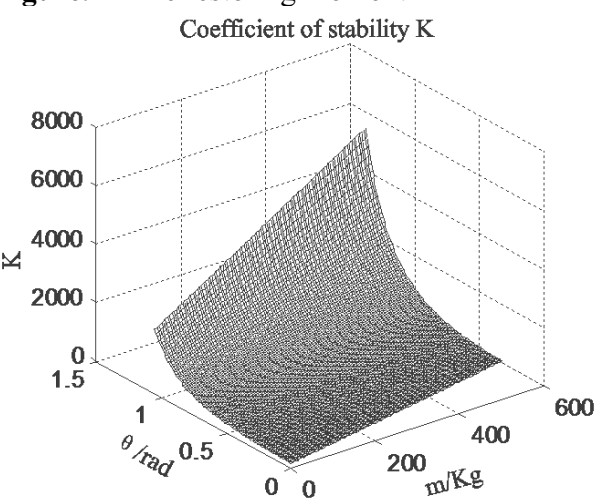

Figure.12 The coefficient of stability

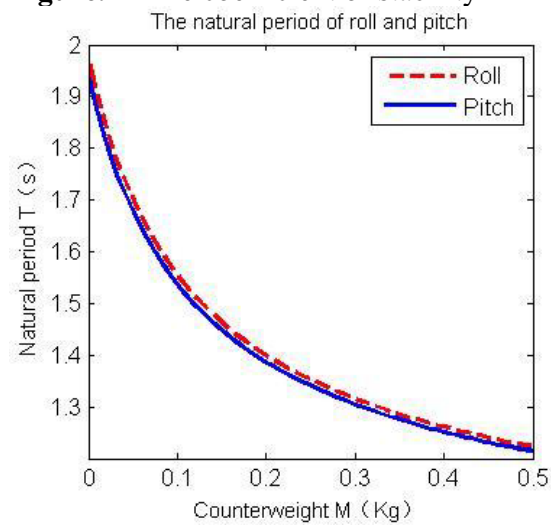

Figure.12 The natural period of roll and pitch

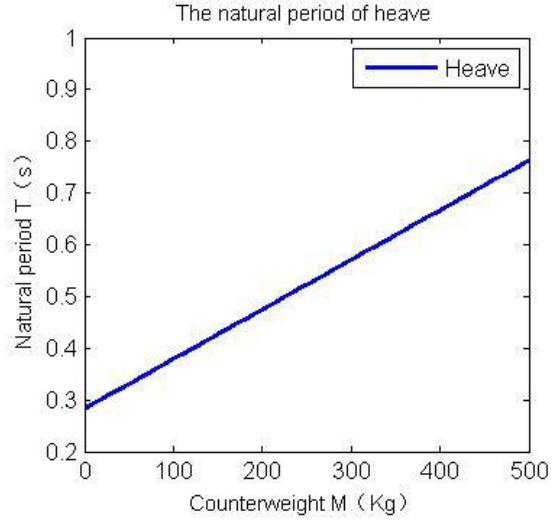

Figure.14 The natural period of heave

Figure.10 shown the height of stability is increased when counterweight is become bigger. Especially the restoring moment and the stability coefficient in a big tilt angle of the platform, which is shown in Figure.11 to Figure.12.

Figure.13 and Figure.14 show the natural period of roll and pitch would reduced and the natural period of heave would increase while the counter weight become bigger.

\subsection{The influence of floating body diameter}

In this part, the floating body diameter is changed in section of $[1,2] \mathrm{m}$ and the centre of gravity of the platform will not change. The relationship between the height of stability $(\mathrm{H})$,restoring moment(M) and coefficient of stability $(\mathrm{K})$ with the diameter of floating $\operatorname{body}(\mathrm{D})$ in the change of the tilt angle $(\theta)$ is below.

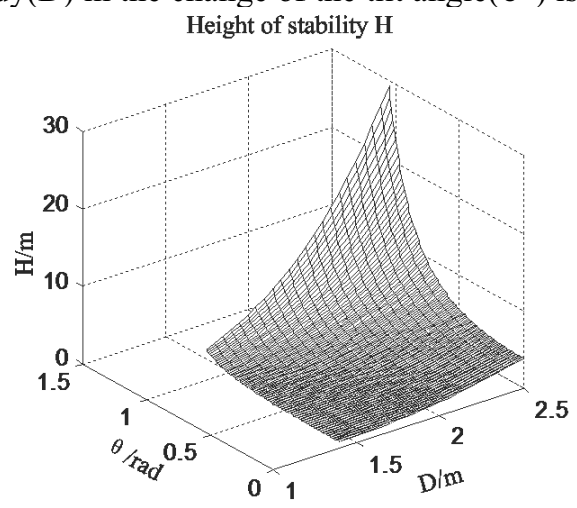

Figure 15. The height of stability.

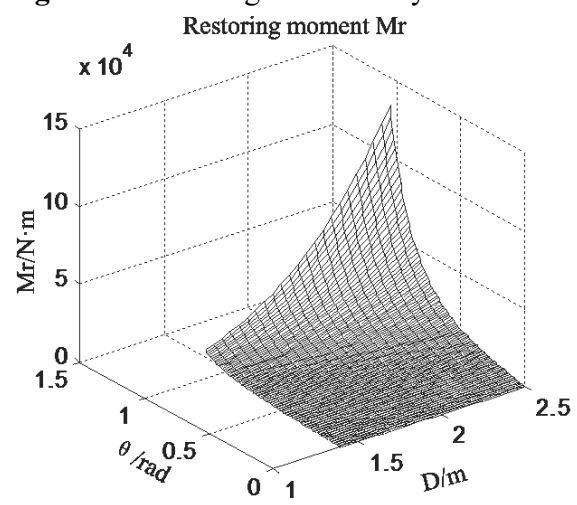

Figure 16. The restoring moment 


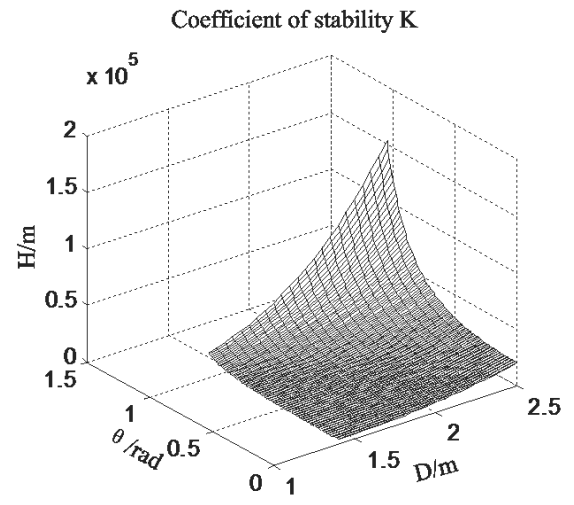

Figure 17. The coefficient of stability

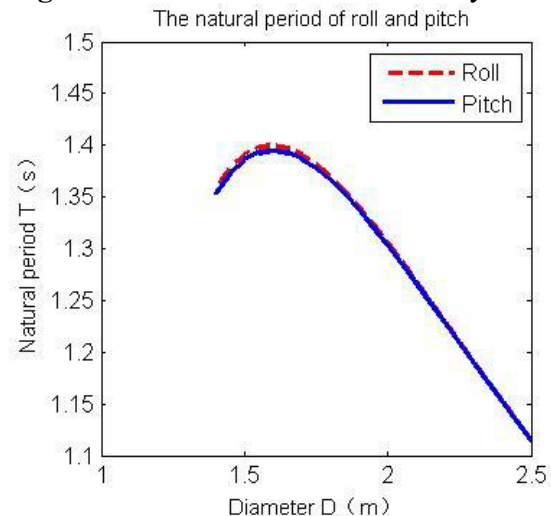

Figure 18. The natural period of roll and pitch

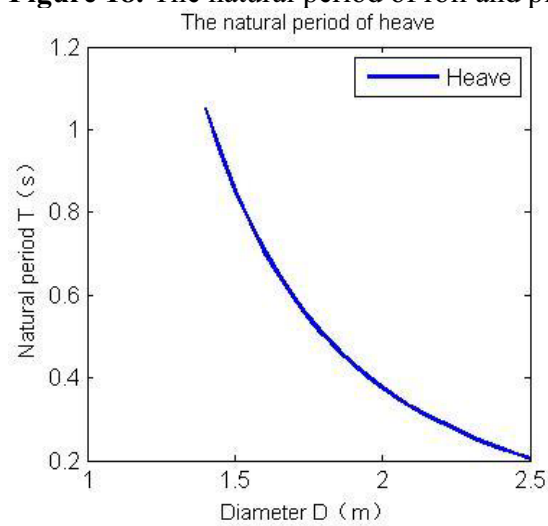

Figure 19. The natural period of heave

Figure. 15 to Figure.17 show the diameter influent the height of stability, restoring moment and stability coefficient significantly, no matter the tilt angle is big or small.

Figure.18 show the period of roll and pitch is increase when $\mathrm{D}<1.6 \mathrm{~m}$, and reduce when $\mathrm{D}>1.6 \mathrm{~m}$.

Figure. 19 show the period of heave is reduce when the diameter become smaller.

\section{Conclusions}

In the effect of three kinds of structure parameters for the hydrostatic properties, the greatest impact is the floating body diameter, followed by the counterweight, by comparing the distance of counterweight, the counterweight and the diameter of floating body for the impact of floating monitoring platform height of stability, the restoring moment and the coefficient of stability.

The natural period of roll, pitch and heave needs to be analyzed according to the structure parameters of concrete by comparing the distance of counterweight, the counterweight, the diameter of floating body for the change of natural period of roll and heave.

In general, the three structural parameters can be an appropriate increase in order to improve the stability of the floating monitoring platform.

\section{Acknowledgement}

The authors would like to thank the support of the Twelfth Five-Year National Science and Technology Major Projects (No.2011ZX05027-004).

\section{References}

1. M.H. Kim. American Society of Civil Engineers. 3477 (2012)

2. F. Zhang, J. Yang, R.P Li, China Offshore Platform. 20(2) 6-11, (2005)

3. J. Zhu Ship statics National University of Defense Technology Press. 34-41(2002)

4. H. Wang Harbin Engineering University. 30-34 (2012)

5. X. Yuan, J.T. Wang Journal of Oceangraphy of Huanghai \& Bohai Seas. 20(2) 118-124. (2012)

6. C. Sun. Electronic University Of Science \&Technology Of Hangzhou. 3 (2014)

7. Ling B. Huazhong University of Science and Technology.19-21

8. J.D. Li the Ship seakeeping Harbin Engineering University Press. 34-45 (2007)

9. Y.J. Wang, Production and application of FRP and composite materials HeFei University of Technology press. 6-31 (2007)

10. Y.Q. Liu, F.Y. Shen, H.F. He. Development and Application of Materials. 23(5) 30-33 (2007) 